\title{
An Experimental Study: Does the Neuroprotective Effect Increase When Hypothermia Deepens After Traumatic Brain Injury?
}

\author{
Abdullah Sadik Girisgin ${ }^{1, *}$; Erdal Kalkan ${ }^{2}$; Mehmet Ergin ${ }^{1}$; Fatih Keskin $^{2}$; Zerrin Defne Dundar ${ }^{1}$; \\ Sedat Kebapcioglu ${ }^{3}$; Sedat Kocak ${ }^{1}$; Basar Cander ${ }^{1}$ \\ ${ }^{1}$ Department of Emergency Medicine, Meram Medicine Faculty, Necmettin Erbakan University, Konya, Turkey \\ ${ }_{2}^{2}$ Department of Neurosurgery, Meram Medicine Faculty, Necmettin Erbakan University, Konya, Turkey \\ ${ }^{3}$ Department of Emergency Medicine, Medicine Faculty, Mevlana University, Konya, Turkey \\ ${ }^{*}$ Corresponding Author: Sadik Abdullah Girisgin, Department of Emergency Medicine, Meram Medicine Faculty, Necmettin Erbakan University, Konya, Turkey. Tel: +90-3322236496, \\ E-mail:sgirisgin@yahoo.com
}

Received: June 18, 2014; Revised: October 16, 2014; Accepted: November 9, 2014

\begin{abstract}
Background: Experimental approaches have been promising with the use of therapeutic hypothermia after Traumatic Brain Injury (TBI) whereas clinical data have not supported its efficacy.

Objectives: This study aimed to investigate whether using selective deeper brain cooling correlates with a more neuroprotective effect on Intracranial Pressure (ICP) increments following TBI in rats.

Materials and Methods: Adult male Sprague-Dawley rats (mean weight $=300 \mathrm{~g} ; \mathrm{n}=25$ ) were subjected to brain injury using a modified Marmarou method. Immediately after the onset of TBI, rats were randomized into three groups. Selective brain cooling was applied around the head using ice packages. Intracranial Temperature(ICT) and ICP were continuously measured at 0,30, 60, 120, and 180 minutes and recorded for all groups. Group $1(n=5)$ was normothermia and was assigned as the control group. Group $2(n=10)$ received moderate hypothermia with a target ICT of between $32^{\circ} \mathrm{C}-33^{\circ} \mathrm{C}$ and Group $3(n=10)$ was given a deeper hypothermia with a target ICT of below $32^{\circ} \mathrm{C}$. Results: All subjects reached the target ICT by the 30th minute of hypothermia induction. The ICT was significantly different in Group 2 compared to Group 1 only at the 120 th minute $(\mathrm{P}=0.017)$, while ICP was significantly lower starting from the 30 th minute $(\mathrm{P}=0.015)$. The ICT was significantly lower in Group 3 compared to Groups 1 and 2 starting from the 30th minute $(P=0.001$ and $P=0.003$, respectively). The ICP was significantly lower in Group 3 compared to Group 1 starting from 30 th minute $(P=0.001)$; however, a significant difference in ICP between Group 3 and Group 2 was observed only at the 180th minute $(P=0.047)$.

Conclusions: Results of this study indicate that selective brain cooling is an effective method of decreasing ICP in rats; however, the deeper hypothermia caused a greater decrease in ICP three hours after hypothermia induction.
\end{abstract}

Keywords: Injuries; Brain Injuries; Hypothermia

\section{Background}

Worldwide, about one million people die annually and 10 million are seriously injured in motor vehicle accidents that cause the majority of all Traumatic Brain Injuries (TBIs). Although mortality rates have diminished over past few years in the United States and other developed countries, low-income countries have the highest mortality rates in treating patients with severe closed TBIs (1-3). Despite these facts, treatment options for TBI are limited. Selective brain cooling has been shown to have a significant effect on Intracranial Pressure (ICP) increments during experimental studies whereas large clinical trials have failed to reproduce positive clinical effects in adults (4-8).

Despite these positive findings of experimental studies, the use of therapeutic hypothermia after TBI remains controversial in humans. Randomized clinical trials of therapeutic hypothermia for severe brain injury can be divided into those trials in which hypothermia was used to treat elevated intracranial pressure and those in which hypothermia was intended as a neuroprotective agent (9). Clinical trials in TBIs have often been underpowered and are challenging because of an intrinsic heterogeneity in the patient population and the absence of mechanical endpoints even without the added complexities of sponsor interference (10). The results of 23 clinical trials of hypothermia treatment involving 1,614 patients with severe brain injuries have been inconsistent (8). A randomized multicenter clinical trial of patients with severe brain injuries in which hypothermia was induced at a very early stage after injury was terminated for futility experienced in these studies. It was reported that there were no significant differences in the outcomes of patient treated with hypothermia; although, patients in the hypothermia group did have a significantly higher number of episodes of increased intracranial pressure than those in the normothermia group (9). However, Maas et al. com-

Copyright ( 2015, Iranian Red Crescent Medical Journal. This is an open-access article distributed under the terms of the Creative Commons Attribution-NonCommercial 4.0 International License (http://creativecommons.org/licenses/by-nc/4.0/) which permits copy and redistribute the material just in noncommercial usages, provided the original work is properly cited. 
mented on this study and stated that this study couldn't put the last point on hypothermia in TBI and there is no reason to exclude patients with diffuse injuries from ongoing trials (10). The translation of animal data into a clinical benefit remains suboptimal. A similar question concerns the efficiency of drugs given during a cardiac arrest. Drug administration in animal studies of cardiac arrest does not reflect human clinical experience (11). A study showd three important factors that determine the successful translation of preclinical research into clinical development: to test the right compound in the right model, using the right endpoint (12). Reynolds et al. (11) showed that the mean time to the first drug administration for cardiac arrest in 2,378 animals was 9.5 minutes (range 3.0 - 28.0; 95\% CI 2.78 - 16.22), which was less than the time reported in clinical trials $(19.4$ minute, $\mathrm{P}<0.001$ ) (13). Thus, clinically these drugs are given during the late metabolic phase of a cardiac arrest; therefore, it is not surprising they are ineffective because of the time to a drug-predicted return of spontaneous circulation. When the differences between animal studies and clinical experiences for hypothermia after TBI are interpreted, we should consider the length of time between the initiation of hypothermia and the critical Intracranial Temperature (ICT) target after TBI. Additionally, consideration should be given as to which procedures are used and the time duration for acceptable rewarming of the patient.

\section{Objectives}

This study aimed to investigate whether selective brain cooling at lower temperatures correlates with a greater neuroprotective effect on ICP increments occurring during TBI in rats.

\section{Materials and Methods}

This was an experimental study that the ethical and experimental committee at the Selcuk University Meram School of Medicine approved (with approval no of 200518 at 10.06.2005). All investigators complied with the Guide for the Care and Use of Laboratory Animals (1996). All efforts were undertaken to reduce the total number of animals used and to minimize their discomfort. The number of animals assigned to each group was allowed according to decision of ethical and experimental committee.

\subsection{Overview of the Experimental Animal Groups}

Adult male Sprague-Dawley rats (mean weight 300 g; n $=25$ ) were used in the experiment. All animals were kept under a 12 hour/12 hour light/dark cycle at a constant temperature $\left(22^{\circ} \mathrm{C}\right)$ and allowed free access to food and tap water. Before the onset of TBI, animals were randomly assigned using the excel random number generator. Selective brain cooling was applied around the head using ice packages. Groups $1(n=5)$ were maintained at normothermia and were assigned as the control group. Group 2 $(\mathrm{n}=10)$ received moderate hypothermia and had a target ICT of between $32^{\circ} \mathrm{C}-33^{\circ} \mathrm{C}$ and Group $3(\mathrm{n}=10)$ received a deeper hypothermia with a target ICT of below $32^{\circ} \mathrm{C}$.

\subsection{Induction of Traumatic Brain Injury}

Animals were anesthetized with a mixture of ketamine HCL (50 mg/kg IP) and xylazine HCL (10 mg/kg IP). All rats were noninvasively monitored using a transcutaneous measurement device for heart rate. They were placed in the prone position. The scalp was prepared with betadine, incised, and the periosteum reflected. A mini-burr hole was placed $1.2 \mathrm{~mm}$ lateral to the midline for ICT and ICP measurements. A metal round plate (diameter $10 \mathrm{~mm}$, width $3 \mathrm{~mm}$ ) was fixed on the skull, midway between the coronal and lambdoid sutures, with dental cement. A diffuse TBI device previously described by Marmarou et al. (14) was used with alterations in the height of the weight and the type of the bed. This injury device consisted of one Plexiglas tube, $1.5 \mathrm{~m}$ long (19 mm inner diameter), attached to a ring stand. The rat was placed in a prone position on the sponge bed and fixed by an elastic band with its head parallel to the ground. The sponge and rat together were slid under the Plexiglas tube. The metal disc located on the rat's cranium was centered under the lower outlet of the tube. A 100-g weight was dropped from a height of one meter in the Plexiglas tube. After the removal of the metal disc, the ICP and ICT were monitored.

\subsection{Induction of Hypothermia}

Cranial cooling was accomplished by placing latex glove fingers filled with crushed ice on the subject's scalp. A single glove finger was used in the moderate hypothermia group while two glove fingers were used in the deeper hypothermia group. The body temperatures of the subjects were also monitored and rewarming was planned in case of lowered body temperature or the development of bradycardia.

\subsection{Temperature and Pressure Measurements}

In our experiment, brain cooling was randomly performed immediately after TBI. The same researcher had taken all measurements for ICT and ICP taken at 0, 30, 60, 120 , and 180 minutes, that were invasively monitored (by Integra Neurocare Camino MPM-1®), recorded and assessed for all groups. Body temperatures of animals were measured with noninvasive monitoring and kept constant and in normal ranges. Once all the measurements were taken the animals were sacrificed. Sacrifices were performed with a cervical dislocation under deep anesthesia with a mixture of ketamine hydrochloride (HCL) (50 mg/kg IP) and xylazine HCL (10 mg/kg IP).

\subsection{Statistical Analyses}

All computations were performed using SPSS statistical software (Version 10.0; SPSS Inc., Chicago, IL). Data are pre- 
sented as the Mean \pm Standard Deviation. A Tukey's multiple comparison tests and One-way ANOVA were used for statistical analyses. $\mathrm{P}<0.05$ was considered to be statistically significant.

\section{Results}

Commencement of selective brain cooling was successfully established within one minute following TBI. The target brain temperature was reached within 60 minutes for Group 2 and 30 minutes for Group 3 after the induction of selective brain cooling. The mean brain temperature was kept stable within the target range throughout the study period of 180 minutes in both hypothermic groups (Figure 1). The ICP also started to decrease in Group 2 and 3 after 30 minutes whereas there was no such decrease in Group 1 (Figure 2). In terms of ICT, there were significant differences between groups at 30, 60, 120, and 180 minutes (Multiple Comparison Test; $\mathrm{P}=0.001 ;<0.001 ;<0.001 ;$ and $<0.001$, respectively). The statistical differences were also found at 30, 60,120, and 180 minutes for ICP (Multiple Comparison Test; $\mathrm{P}=0.001$; $<0.001$; $<0.001$; and $<0.001$, respectively). When we compared groups with each other in terms of ICT, we found there were statistically significant differences at 120 and 180 minutes between Groups 1 and 2 (One-way ANOVA; $\mathrm{P}=0.017$ and 0.046 , respectively); at 30, 60, 120, and 180 minutes between Groups 1 and 3 (One-way ANOVA; P = $0.001,<0.001,<0.001$, and < 0.001, respectively); and at 30,60, 120, and 180 minutes between Groups 2 and 3 (one-way ANOVA; $\mathrm{P}=0.003,<0.001,<0.001$, and $<0.001$, respectively; Table 1 . When comparing groups with each other in terms of ICP, we found there were statistically significant differences at 30,60,120, and 180 minutes between Groups 1 and 2 (One-way ANOVA; $\mathrm{P}=0.015,<0.001$, $<0.001$, and $<0.001$, respectively); at 30, 60,120, and 180 minutes between Groups 1 and 3 (One-way ANOVA; $\mathrm{P}=$ $0.001,<0.001,<0.001$, and $<0.001$, respectively); and at 180 minutes between Groups 2 and 3 (One-way ANOVA; P $=0.047$; Table 1 ).

\section{Discussion}

Several studies have demonstrated that TBI in rats causes significant changes in the biomarker levels of extracellular fluid ischemia and injury in addition to increased ICP together with a decreased cerebral perfusion pressure $(4,5,15)$. Numerous experimental studies have shown positive effects of local hypothermia on ICP (4-7). Our study demonstrated that there were significant reductions in ICP in Groups 2 and 3 compared to the control group 30 minutes after the TBI, which was in accordance with previous studies.

Cerebral infarction, biochemical, behavioral and body weight loss assessments have also been conducted in experimental TBI studies in rats. It has been reported that selective brain cooling improves the outcomes of TBI by reducing intracranial hypertension as well as reducing cerebral ischemia and infarction, motor and proprioception deficits, and body weight loss in rats $(4,16)$. Another study found that nitrosative damage, oxidative damage, cerebral apoptosis and contusion, and behavioral deficits occurring during TBI were all reduced by selective brain cooling in rats without prominent side effects (5). Alternatively, DeKosky et al. showed that postinjury hypothermia resulted in a reduction of antioxidant enzyme activity that a nerve growth factor infusion could not correct (15). Doll et al. showed that a selective brain cooling method called "pharyngeal selective brain cooling" was associated with improved neurofunctional, sensorimotor, and neurocognitive recovery following TBI in rats (17). These positive findings with behavioral factors were substantiated by brain histo-morphological outcomes that included preservation of cortical tissue ipsilateral to the lesion and superior physical recovery with reduced weight loss in the acute phase post-injury and a more robust weight gain thereafter (18). The neuroprotective mechanisms provided by hypothermia include a reduction of cerebral lactate accumulation, stimulation of angiogenesis and neurogenesis, a reduction of oxidative stress, suppressed overproduction of cytokines and a hypercoagulable state.

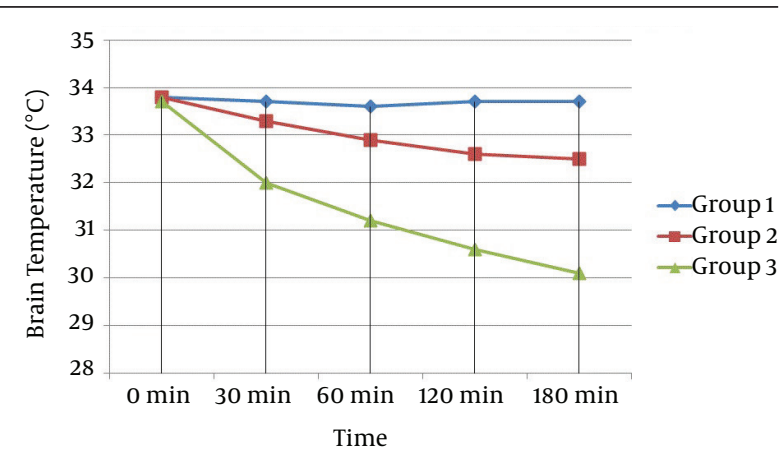

Figure 1. Curve Showing the Mean Value of Brain Temperature of All Groups Against Time

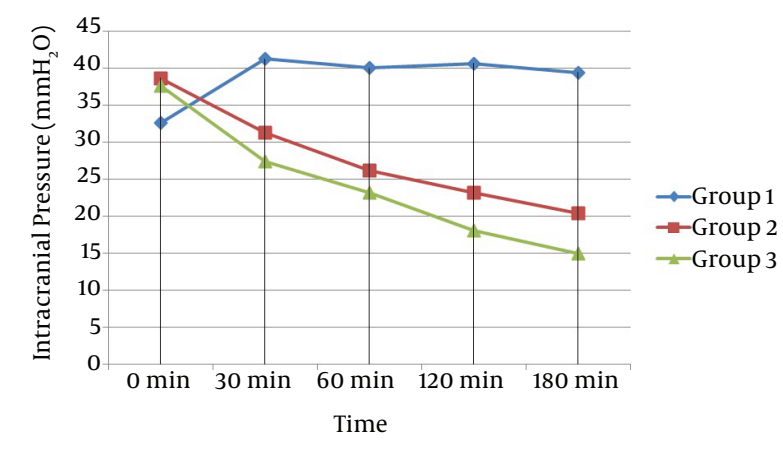

Figure 2. Curve Showing the Mean Value of Intracranial Pressure Curves of All Groups Against Time. 
Girisgin AS et al.

\begin{tabular}{|c|c|c|c|c|c|}
\hline Groups & $0 \mathrm{~min}$ & $30 \mathrm{~min}$ & $60 \mathrm{~min}$ & $120 \mathrm{~min}$ & $180 \mathrm{~min}$ \\
\hline \multicolumn{6}{|l|}{ Group 1} \\
\hline ICT & $33.8 \pm 0.2$ & $33.7 \pm 0.2$ & $33.7 \pm 0.2$ & $33.7 \pm 0.2$ & $33.6 \pm 0.2$ \\
\hline ICP & $32.6 \pm 4.9$ & $41.2 \pm 5.6$ & $40.0 \pm 5.5$ & $40.6 \pm 4.9$ & $39.4 \pm 6.2$ \\
\hline \multicolumn{6}{|l|}{ Group 2} \\
\hline ICT & $33.8 \pm 0.3$ & $33.3 \pm 0.4$ & $32.9 \pm 0.2$ & $32.6 \pm 0.3$ & $32.5 \pm 0.5$ \\
\hline ICP & $38.6 \pm 9.5$ & $31.2 \pm 7.1^{b}$ & $26.1 \pm 5.4 \mathrm{~b}$ & $23.1 \pm 52^{b}$ & $20.4 \pm 5.1^{b}$ \\
\hline \multicolumn{6}{|l|}{ Group 3} \\
\hline ICT & $33.7 \pm 0.3$ & $32.0 \pm 1.2^{b, c}$ & $31.2 \pm 0.9^{b, c}$ & $30.6 \pm 0.9 \mathrm{~b}, \mathrm{c}$ & $30.1 \pm 1.2^{b, c}$ \\
\hline ICP & $37.6 \pm 6.1$ & $27.4 \pm 4.6^{b}$ & $23.2 \pm 3.6^{\mathrm{b}}$ & $18 \pm 3.8^{b}$ & $14.9 \pm 3.8^{b, c}$ \\
\hline
\end{tabular}

a Abbreviations: ICT, intracranial temperature; ICP, intracranial pressure; Group 1, control group; Group 2, moderate hypothermia; Group 3, deep hypotherm.

b $\mathrm{P}<0.05$, compared to group 1 .

c $\mathrm{P}<0.05$, compared to group 2 .

Moreover, there is a reversal of intracellular calcium influx with the protection of high energy phosphates, decreased glutamate release in the core of infarction, and an inhibited release of neurotransmitters and free fatty acids with ischemia $(4,5,12,13,16,19,20)$.

In our study, the ICT was lower in the moderate hypothermia group (Group 2) compared to the control group (Group 1) starting from the 30th minute; however, this difference was only considered significant at the 120th minute of observation. Alternatively, the ICP was lowered significantly starting from the 30th minute in the moderate hypothermia group when compared with Group 1. The ICT and ICP in the deeper hypothermia group (Group 3) were significantly lower compared to the other groups from the 30th minute onward. While the ICP was also lower in the moderate hypothermia group, the difference between hypothermic groups was statistically significant only for the reading at the 180th minute. These results showed that even though induction of hypothermia lowers the ICP starting at 30 minutes, no statistically significant results are seen in moderate and deep hypothermia groups until 180 minutes.

In conclusion, the findings of this study indicate that selective brain cooling is an effective method of decreasing ICP in rats. However, the deeper hypothermia can cause greater decreases in ICP after three hours. Further studies in animals with higher body temperatures (i.e. higher than those observed in rats) and greater ranges between the moderate and deeper hypothermia may provide more precise results and will be needed to confirm our results.

\subsection{Limitations}

The limitations of our study were the baseline body temperatures of rats being under $35^{\circ} \mathrm{C}$ and the closeness of ICT target intervals in the hypothermia groups, and the statistical relationship between the moderate hypothermia and the control groups. Studies with wider tar- get temperature differences (e.g. ICT under $30^{\circ} \mathrm{C}$ ) can be performed in the future with potentially better results yielding an understanding of changes in ICP.

We thought that the weak point of our study was the low number of test subjects. As we mentioned, it was determined by decision of the ethical committee. In our opinion, our cooling method was simple and easily applied by anyone, which is the strongest point of our study. Our results were supportive in terms of induction of hypothermia after TBIs. We also thought that our results might stimulate other researchers to find out whether deeper hypothermia provides more protective effect on intracranial pressure.

\section{Authors' Contributions}

Study concept and design: Sadik Abdullah Girisgin. Acquisition of data: Sadik Abdullah Girisgin, Erdal Kalkan, and Fatih Keskin. Analysis and interpretation of data: Zerrin Defne Dundar, and Sedat Kocak. Drafting of the manuscript: Sadik Abdullah Girisgin, and Mehmet Ergin. Critical revision of the manuscript for important intellectual content: Sadik Abdullah Girisgin, Mehmet Ergin, and Sedat Kebapcioglu. Statistical analysis: Zerrin Defne Dundar. Administrative, technical, and material support: Sadik Abdullah Girisgin, Erdal Kalkan, Fatih Keskin, and Basar Cander. Study supervision: Sadik Abdullah Girisgin.

\section{References}

1. Georgoff P, Meghan S, Mirza K, Stein SC. Geographic variation in outcomes from severe traumatic brain injury. World Neurosurg. 2010;74(2-3):331-45.

2. World Health Organization . In: World report on road traffic injury prevention: summary. World Health Organization, editor. Genova: 2004.

3. Hofman K, Primack A, Keusch G, Hrynkow S. Addressing the growing burden of trauma and injury in low- and middle-income countries. Am J Public Health. 2005;95(1):13-7.

4. Chio CC, Kuo JR, Hsiao SH, Chang CP, Lin MT. Effect of brain cooling on brain ischemia and damage markers after fluid percussion brain injury in rats. Shock. 2007;28(3):284-90. 
5. Kuo JR, Lo CJ, Chang CP, Lin MT, Chio CC. Attenuation of brain nitrostative and oxidative damage by brain cooling during experimental traumatic brain injury. J Biomed Biotechnol. 2011;2011:145214.

6. Celik SE, Ozturk H, Tolunay S. Therapeutic effect of hypothermia and dizocilpine maleate on traumatic brain injury in neonatal rats. J Neurotrauma. 2006;23(9):1355-65.

7. Lee HC, Chuang HC, Cho DY, Cheng KF, Lin PH, Chen CC. Applying cerebral hypothermia and brain oxygen monitoring in treating severe traumatic brain injury. World Neurosurg. 2010;74(6):654-60.

8. Sydenham E, Roberts I, Alderson P. Hypothermia for traumatic head injury. Cochrane Database Syst Rev. 2009(2):CD001048.

9. Clifton GL, Valadka A, Zygun D, Coffey CS, Drever P, Fourwinds S, et al. Very early hypothermia induction in patients with severe brain injury (the National Acute Brain Injury Study: Hypothermia II): a randomised trial. Lancet Neurol. 2011;10(2):131-9.

10. Maas A, Stocchetti N. Hypothermia and the complexity of tri als in patients with traumatic brain injury. Lancet Neurol. 2011;10(2):111-3.

11. Reynolds JC, Rittenberger JC, Menegazzi JJ. Drug administration in animal studies of cardiac arrest does not reflect human clinical experience. Resuscitation. 2007;74(1):13-26.

12. Baker CJ, Fiore AJ, Frazzini VI, Choudhri TF, Zubay GP, Solomon RA. Intraischemic hypothermia decreases the release of glutamate in the cores of permanent focal cerebral infarcts. Neurosurgery. 1995;36(5):994-1001.

13. Busto R, Dietrich WD, Globus MY, Valdes I, Scheinberg P, Ginsberg MD. Small differences in intraischemic brain temperature criti- cally determine the extent of ischemic neuronal injury. J Cereb Blood Flow Metab. 1987;7(6):729-38.

14. Marmarou A, Lu J, Butcher I, McHugh GS, Mushkudiani NA, Murray GD, et al. IMPACT database of traumatic brain injury: design and description. J Neurotrauma. 2007;24(2):239-50.

15. DeKosky ST, Abrahamson EE, Taffe KM, Dixon CE, Kochanek PM, Ikonomovic MD. Effects of post-injury hypothermia and nerve growth factor infusion on antioxidant enzyme activity in the rat: implications for clinical therapies. J Neurochem. 2004;90(4):998-1004.

16. Kuo JR, Lo CJ, Chang CP, Lin HJ, Lin MT, Chio CC. Brain cooling stimulated angiogenesis and neurogenesis attenuated traumatic brain injury in rats. JTrauma. 2010;69(6):1467-72.

17. Doll H, Truebel H, Kipfmueller F, Schaefer U, Neugebauer EA, Wirth S, et al. Pharyngeal selective brain cooling improves neurofunctional and neurocognitive outcome after fluid percussion brain injury in rats. J Neurotrauma. 2009;26(2):235-42.

18. Doll H, Maegele M, Bohl J, Storkel S, Kipfmueller F, Schaefer U, et al. Pharyngeal selective brain cooling is associated with reduced CNS cortical lesion after experimental traumatic brain injury in rats. J Neurotrauma. 2010;27(12):2245-54.

19. Hsu SF, Niu KC, Lin CL, Lin MT. Brain cooling causes attenuation of cerebral oxidative stress, systemic inflammation, activated coagulation, and tissue ischemia/injury during heatstroke. Shock. 2006;26(2):210-20.

20. Laptook AR, Corbett RJ, Burns D, Sterett R. Neonatal ischemic neuroprotection by modest hypothermia is associated with attenuated brain acidosis. Stroke. 1995;26(7):1240-6. 